\title{
Long-Term Stability of a Portable Carbon Monoxide Single-Breath Diffusing Capacity Instrument
}

\author{
Laura Gochicoa-Rangel MD MSc, Rogelio Pérez-Padilla MD, \\ Juan Carlos Vázquez-García MD MSc, Mónica Silva-Cerón, Silvia Cid-Juárez MD MSc, \\ David Martínez-Briseño MSc, Paul L Enright MD, Robert Jensen PhD, and \\ Luis Torre-Bouscoulet MD MSc
}

\begin{abstract}
BACKGROUND: The 2005 American Thoracic Society/European Respiratory Society guidelines for single-breath diffusing capacity of the lung for carbon monoxide $\left(\mathrm{D}_{\mathrm{LCO}}\right)$ recommend a weekly biological control test and/or $D_{\mathrm{LCO}}$ simulator to detect instrument error drift. Very little has been published regarding the results of such a quality assurance program. Our aim was to analyze the long-term stability of a portable $D_{L C O}$ instrument. METHODS: We used a new EasyOne Pro system and checked its accuracy using a $D_{L C O}$ simulator with 2 reference gases (concentration $A$ : carbon monoxide $[\mathrm{CO}]=0.1 \%$ and helium $=6.52 \%$; concentration $\mathrm{B}$ : $\mathrm{CO}=0.08 \%$ and helium $=\mathbf{7 . 2 1} \%$ ) during the first $3 \mathrm{y}$ of use in our large clinical laboratory. To detect instrument drift, a healthy woman (MSC), age $43 \mathrm{y}$ old at baseline, tested herself every week during this period of time. RESULTS: More than 6,000 spirometry and 5,000 $\mathrm{D}_{\mathrm{LCO}}$ maneuvers were done using this instrument for patients during these $3 \mathrm{y}$. There were no failures in the daily volume and flow checks or the $\mathrm{CO}$ and helium calibration checks performed automatically by the instrument. The differences between the simulator $D_{L C O}$ and the measured $D_{L C O}$ were $-0.91 \pm 1.33 \mathrm{~mL} / \mathrm{min} / \mathrm{mm} \mathrm{Hg}$ and $-0.61 \pm 1.45 \mathrm{~mL} / \mathrm{min} / \mathrm{mm} \mathrm{Hg}$ for concentration $\mathrm{A}$ and concentration $\mathrm{B}$, respectively. The results of the 110 biological control tests were: mean $30.8 \pm 1.7 \mathrm{~mL} / \mathrm{min} / \mathrm{mm} \mathrm{Hg} \mathrm{(95 \%} \mathrm{CI} \mathrm{30.5-}$ 31.1), coefficient of variation of $5.4 \%$ in $D_{L C O}$, and repeatability of $2.5 \mathrm{~mL} / \mathrm{min} / \mathrm{mm} \mathrm{Hg}$. Only 4 measurements were outside $\pm 3 \mathrm{~mL} / \mathrm{min} / \mathrm{mm} \mathrm{Hg}(3.6 \%)$. Her mean alveolar volume was $4.2 \pm 0.25 \mathrm{~L}$ with coefficient of variation of $6.2 \%$; her inspired volume was $3.05 \pm 0.14 \mathrm{~L}$, and coefficient of variation $=4.5 \%$. CONCLUSIONS: Measurements of $D_{L C O}$ were stable over the 3-y period without any need for manual recalibration of the instrument. The biological control was as good as the $D_{\mathrm{LCO}}$ simulator to evaluate this kind of device in a long-term laboratory quality control program. Key words: diffusing capacity for carbon monoxide; biological control; quality control; simulator. [Respir Care 2017;62(2):231-235. (C) 2017 Daedalus Enterprises]
\end{abstract}

\section{Introduction}

Single-breath diffusing capacity of the lung for carbon monoxide $\left(\mathrm{D}_{\mathrm{LCO}}\right)$ tests have considerable clinical value

Dr Gochicoa-Rangel, Dr Pérez-Padilla, Dr Vázquez-García, Ms SilvaCerón, Dr Cid-Juárez, and Dr Torre-Bouscoulet are affiliated with the Departamento de Fisiología Respiratoria, Instituto Nacional de Enfermedades Respiratorias "Ismael Cosío Villegas," México, Distrito Federal, México. Mr Martínez-Briseño is affiliated with the Departamento de Investigación en Epidemiología y Ciencias Sociales en Salud, Instituto Nacional de Enfermedades Respiratorias "Ismael Cosío Villegas," for detecting the emphysema COPD phenotype and for changing the pretest probability of an interstitial lung dis-

México. Dr Enright is affiliated with the Department of Medicine, University of Arizona, Tucson, Arizona. Dr Jensen is affiliated with the Department of Medicine, Pulmonary Division, University of Utah, Salt Lake, Utah.

Dr Gochicoa-Rangel presented a version of this paper at the 2015 European Respiratory Society International Conference, held September 2630, 2015, in Amsterdam, Netherlands.

The authors have disclosed no conflicts of interest. 
ease or pulmonary vascular disease in patients with dyspnea. ${ }^{1}$ Once a diagnosis is established, a change in $\mathrm{D}_{\mathrm{LCO}}$ can help to determine treatment response or disease progression. However, the accuracy and reproducibility of $\mathrm{D}_{\mathrm{LCO}}$ results from one laboratory to another has been highly variable, causing an increased rate of misclassification in interpretations. ${ }^{2,3}$ We have previously reported the quality of spirometry tests done in our laboratory, ${ }^{4,5}$ but very little has been published regarding the results of $D_{\text {LCO }}$ quality assurance programs in clinical pulmonary function testing (PFT) laboratories, so our aim was to analyze the results for a new $\mathrm{D}_{\mathrm{LCO}}$ instrument and report it here. We hypothesized that the $\mathrm{D}_{\mathrm{LCO}}$ device is a stable long-term clinical instrument and that both simulator and biological-based quality control strategies may be appropriate in terms of follow-up.

\section{Methods}

In 2010, we acquired an EasyOnePro system (ndd Medical Technologies, Zurich, Switzerland) to measure FVC, slow $\mathrm{VC}$, and $\mathrm{D}_{\mathrm{LCO}}$ for patients referred to our large clinical laboratory in México City (altitude 2,250 m). Before placing the instrument into clinical use, we verified the accuracy of $\mathrm{D}_{\mathrm{LCO}}$ measurements using a $\mathrm{D}_{\mathrm{LCO}}$ simulator (series 5560, Hans Rudolph, Shawnee, Kansas), testing with 2 different $1 \%$ precision reference gases, (concentration $\mathrm{A}$ : carbon monoxide $[\mathrm{CO}]=0.1 \%$ and helium $=6.52 \%$; concentration $\mathrm{B}: \mathrm{CO}=0.08 \%$ and helium $=7.21 \%$ ), producing $\mathrm{D}_{\mathrm{LCO}}$ target values of about 10 , 20, and 35 units, calculated using EasyLab software, with inspired volumes from 2-5 L. A difference from target of $\pm 2.0 \mathrm{D}_{\mathrm{LCO}}$ units was used as the threshold to initiate an investigation into possible causes of error. ${ }^{6}$ Throughout this paper, for easier reading, we will use the term units in place of $\mathrm{mL} / \mathrm{min} / \mathrm{mm} \mathrm{Hg}$. The instrument checked the accuracy of the $\mathrm{CO}$ and helium sensors automatically before each test session by performing a 5-point calibration using test gas, mixed gas, and ambient air. This calibration allows automatic determination of sensor gain, offset, and drift. As an additional component of our instrument quality assurance program, we routinely tested a biological control subject, a healthy woman (MSC), age 43 y old at baseline, who tested herself every week. Two $\mathrm{D}_{\mathrm{LCO}}$ maneuvers were done to obtain repeatability matching. The same healthy woman measured slow VC as well as FVC

\footnotetext{
Correspondence: Luis Torre-Bouscoulet MD MSc, Departamento de Fisiología Respiratoria, Instituto Nacional de Enfermedades Respiratorias, “Ismael Cosío Villegas," Tlalpan 4502, Colonia Sección XVI Delegación Tlalpan CP 14080, México. E-mail: luistorreb@gmail.com.
}

DOI: $10.4187 /$ respcare.04983

\section{QUICK LOOK}

\section{Current knowledge}

The 2005 American Thoracic Society/European Respiratory Society guidelines for single-breath diffusing capacity of the lung for carbon monoxide $\left(\mathrm{D}_{\mathrm{LCO}}\right)$ recommend a weekly biological control test and/or $\mathrm{D}_{\mathrm{LCO}}$ simulator to detect instrument error drift. Very little has been published regarding the results of such a quality assurance program.

\section{What this paper contributes to our knowledge}

Our study demonstrates that measurements of $\mathrm{D}_{\mathrm{LCO}}$ were stable over the 3 -y period without any need for manual recalibration of the instrument. The biological control was as good as the $\mathrm{D}_{\mathrm{LCO}}$ simulator to evaluate this kind of device in a long-term laboratory quality control program.

each week. Her baseline $\mathrm{D}_{\mathrm{LCO}}$ and short-term variability were determined from her first 20 tests. The instrument was then considered "out of control" if her current $D_{\text {LCO }}$ was outside of her baseline range. Instrument troubleshooting would then be performed to determine the cause of the $\mathrm{D}_{\mathrm{LCO}}$ drift. During the $3 \mathrm{y}$ of use, we checked the absolute $\mathrm{D}_{\mathrm{LCO}}$ accuracy using the $\mathrm{D}_{\mathrm{LCO}}$ simulator. The accuracy of the ultrasonic flow sensor was checked at the beginning of each testing day using a 3.0-L calibration syringe (CareFusion, Hoechberg, Germany) for volume and flow check and every week at 3 different flows for linearity, for both inspired and expired volumes. The acceptable range was 2.91-3.09 L $( \pm 3 \%)^{7}$

Patient testing was done according to 2005 American Thoracic Society/European Respiratory Society (ATS/ERS) guidelines for spirometry and $\mathrm{D}_{\mathrm{LCO}}{ }^{8}$ Instrument software versions during this period of time were from 1.1.7.0 to 1.4.1.0. Four different PFT technologists, with National Institute for Occupational Safety and Health certificates for spirometry, all with at least $8 \mathrm{y}$ of experience, used the instrument (and others) to test patients referred to the PFT laboratory. Certification of PFT technologists for $\mathrm{D}_{\mathrm{LCO}}$ is not available in México. Reference equations used for spirometry and $\mathrm{D}_{\mathrm{LCO}}$ were from Pérez-Padilla et $\mathrm{al}^{9}$ and Crapo et al, ${ }^{10}$ respectively. ${ }^{11}$ An acceptable $\mathrm{D}_{\mathrm{LCO}}$ maneuver had a breath-hold time from 8 to $12 \mathrm{~s}$, a test gas inspired volume $>85 \%$ of the largest vital capacity (slow VC or FVC), an inspiratory time $\leq 4 \mathrm{~s}$, and a sample volume $\geq 0.1 \mathrm{~L}$. The instrument displays error messages whenever a maneuver is not acceptable according to these standards. A good quality $\mathrm{D}_{\mathrm{LCO}}$ test session included at least 2 acceptable $\mathrm{D}_{\mathrm{LCO}}$ results, which matched within 3.0 units. The instrument displays and prints a $\mathrm{D}_{\mathrm{LCO}}$ quality grade 
Table 1. Single-Breath Diffusing Capacity of the Lung for Carbon Monoxide Maneuver Acceptability

\begin{tabular}{lc}
\hline \multicolumn{1}{c}{ Criteria } & Acceptability Rate (\%) \\
\hline Inspired VC $>80 \%$ VC target & 92.8 \\
Breath-hold time 8-12 s & 94.4 \\
Inspiratory time $<4 \mathrm{~s}$ & 98.8 \\
Sample volume $>0.1 \mathrm{~L}$ & 100 \\
& \\
\hline These results are from 1,850 maneuvers done by 694 consecutive subjects. \\
VC = vital capacity
\end{tabular}

Table 2. Rates for Each Diffusing Capacity of the Lung for Carbon Monoxide Quality Grade

\begin{tabular}{lr}
\hline \hline \multicolumn{1}{c}{ Quality Grade Criteria } & Rate (\%) \\
\hline $\mathrm{A}=2$ tests matching within 1 unit & 51.5 \\
$\mathrm{~B}=2$ tests matching within 2 units & 21.9 \\
$\mathrm{C}=2$ tests matching within 3 units & 9.3 \\
$\mathrm{D}=$ only 1 acceptable test or 2 tests poorly & 3.7 \\
match $>3$ units & 13.6 \\
$\mathrm{~F}=$ otherwise & \\
\hline$N=694$. The quality grade for a diffusing capacity of the lung for carbon monoxide test \\
session is computed according to the number of acceptable maneuvers (tests) and how \\
repeatable they are. Repeatability criteria refer to the 2 nearest values if $>2$ tests were done. \\
A quality grade of A, B, or C requires at least 2 acceptable maneuvers. \\
\hline
\end{tabular}

(A-F) according to the degree of $\mathrm{D}_{\mathrm{LCO}}$ repeatability within the test session. A database within the instrument stored all test results and maneuver graphs as well as calibration checks and biological control results. After $3 \mathrm{y}$ of testing patients, we transferred the accumulated results to a computer for statistical analyses (Stata 13, StataCorp, College Station, Texas). The results were summarized as the coefficient of variation $=\mathrm{SD} /$ mean, and repeatability was summarized as $1.96 \times \mathrm{SD}$. Root mean square, coefficient of variation, and range percentiles of intra-subject $D_{\text {LCO }}$ test values were calculated. The ethics committee of our institution approved the study, and the tested biological control gave her written informed consent.

\section{Results}

More than 6,000 FVC, 2,000 slow VC, and 5,000 $\mathrm{D}_{\mathrm{LCO}}$ maneuvers were done using the instrument during the study period. From $694 \mathrm{D}_{\mathrm{LCO}}$ test sessions done for subjects, $86.6 \%$ met ATS/ERS acceptability goals, ${ }^{8}$ and $93.2 \%$ were repeatable within 3 units. The rates of each type of maneuver error are given in Table 1 . The rates for each $D_{L C O}$ quality grade are shown in Table 2 . The within-subject variability of $\mathrm{D}_{\mathrm{LCO}}$ (the degree of matching), expressed as the root mean square coefficient of variation, was 5.4\%, and the repeatability $(1.96 \times \mathrm{SD})$ was 1.57 units.
There were no failures in the daily volume and flow checks using the 3.0-L syringe or the $\mathrm{CO}$ and helium calibration checks performed automatically by the instrument. The differences (or error) between the simulator $\mathrm{D}_{\mathrm{LCO}}$ and the measured $\mathrm{D}_{\mathrm{LCO}}$ were $-0.91 \pm 1.33$ units (95\% CI from -0.94 to -0.89 ) for $\mathrm{CO}$ and helium concentration $\mathrm{A}$ and $-0.61 \pm 1.45$ units for concentration $\mathrm{B}$ (95\% CI from -4.6 to 6.2) (Fig. 1).

The results of the 110 biological control test sessions done by the healthy technologist are plotted in Figure 2. Her mean $\mathrm{D}_{\mathrm{LCO}}$ was $30.8 \pm 0.16$ units (95\% CI $30.5-$ 31.1 , the coefficient of variation was $5.4 \%$, and the repeatability was 2.5 units; during this period, the slow vital capacity was $3.2 \pm 0.08 \mathrm{~L}$ and the FVC was $3.12 \pm 0.09 \mathrm{~L}$, with a coefficient of variation of 2.5 and $2.9 \%$, respectively. Only $4 \mathrm{D}_{\mathrm{LCO}}$ measurements $(3.6 \%)$ were outside \pm 3 units of her mean value. Her mean alveolar volume was $4.2 \pm 0.25 \mathrm{~L}$ with a coefficient of variation of $6.2 \%$, and her mean inspired volume was $3.05 \pm 0.14 \mathrm{~L}$ (coefficient of variation $=4.5 \%$ ). When the measurements were out of control, the biological control repeated the maneuver, and if the error continued, we informed the distributor of the device. During the 3-y period, we had to perform maintenance 3 times (maintenance includes exchanging a few parts accessible to the user). When the error was high, the problem was resolved by changing the hose that goes from the device to the sensor or by changing the seals; when the error coincided with a respiratory infection suffered by the biological control, the results returned to her mean values after the infection resolved, in that case, we did not make any changes.

\section{Discussion}

Several factors affect the false positive and false negative rates for the interpretation of $\mathrm{D}_{\mathrm{LCO}}$ results. ${ }^{12}$ These include the training and enthusiasm of the technologist performing the tests for meeting guidelines for maneuver acceptability and repeatability ${ }^{13}$; the accuracy and reproducibility of the instrument ${ }^{14}$; the inherent biological variability of the patient (including changes in hemoglobin and carboxyhemoglobin); the degree of $\mathrm{D}_{\mathrm{LCO}}$ impairment (a very low $\mathrm{VC}$ or very low $\mathrm{D}_{\mathrm{LCO}}$ causes low sample volumes, which cause errors in some instruments); the choice of reference equations (especially for very elderly patients and those with non-white ethnicity); thresholds for abnormality $(80 \%$ predicted vs the 5 th percentile lower limit of the normal range); the availability of clinical information that can be used to estimate the pretest probability of various diseases that can affect the $\mathrm{D}_{\mathrm{LCO}}$; and the training, experience, and skill of the physician who interprets the test results (especially those with suboptimal quality). A quality control program for the instrument substantially improves the accuracy and visit-to-visit repro- 


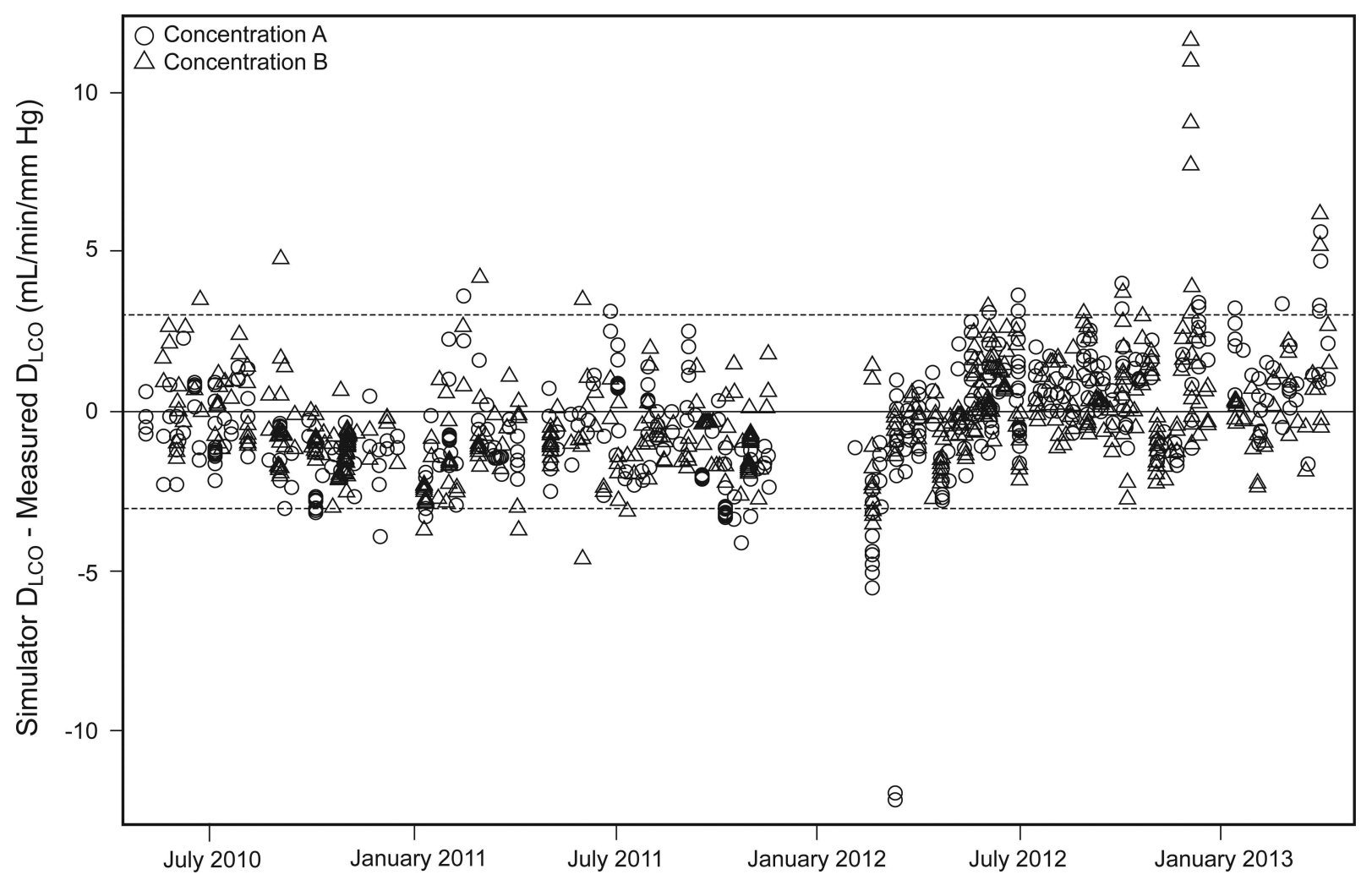

Fig. 1. Differences between the simulator diffusing capacity of the lung for carbon monoxide $\left(D_{\text {LCO }}\right)$ and measured $D_{\text {Lco }}$ during the 3 y of testing hundreds of subjects, at different $\mathrm{CO}$ and helium gas concentrations (concentration $\mathrm{A}: \mathrm{CO}=0.1 \%$ and helium $=6.52 \%$; concentration $\mathrm{B}$ : $\mathrm{CO}=0.08 \%$ and helium $=7.21 \%)$. Dashed lines show $\pm 3 \mathrm{~mL} / \mathrm{min} / \mathrm{mm} \mathrm{Hg}$.

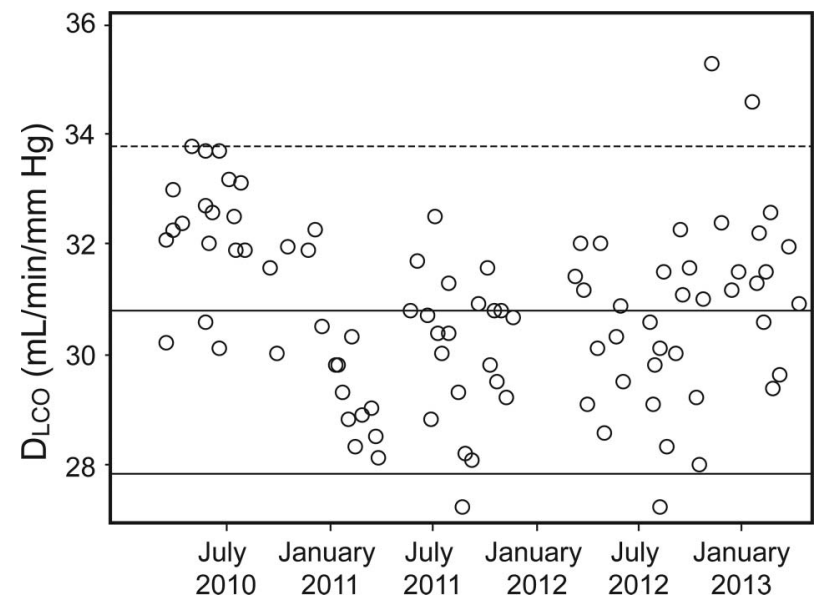

Fig. 2. Variability of bio-quality control diffusing capacity of the lung for carbon monoxide $\left(D_{\text {LCO }}\right)$ values from a healthy technologist over $3 \mathrm{y}$. Dashed lines represent $\pm 3 \mathrm{~mL} / \mathrm{min} / \mathrm{mm} \mathrm{Hg}$ from the mean. Her mean $\mathrm{D}_{\text {LCO }}$ was $30.8 \pm 1.7 \mathrm{SD}$; the coefficient of variation was $5.4 \%$; and the repeatability was $2.5 \mathrm{~mL} / \mathrm{min} / \mathrm{mm} \mathrm{Hg}$. Only 4 measurements (3.6\%) were outside $\pm 3 \mathrm{~mL} / \mathrm{min} / \mathrm{mm} \mathrm{Hg}$ of her mean value.

ducibility of $\mathrm{D}_{\mathrm{LCO}}$ results ${ }^{15-17}$ but does not address the other factors, so a comprehensive approach is needed to minimize misclassification and optimize the value of the test for clinical decision making.
The $\mathrm{D}_{\mathrm{LCO}}$ simulator checks the accuracy of $\mathrm{D}_{\mathrm{LCO}}$ results at 3 levels within the clinical range. At the beginning of a multi-center international study of inhaled insulin, the simulator was used to check the accuracy of the $\mathrm{D}_{\mathrm{LCO}}$ machines (12 different models) used at the PFT laboratories of the 125 study sites. ${ }^{16}$ Equipment at one fourth of those sites failed the initial $\mathrm{D}_{\mathrm{LCO}}$ simulation testing. After correcting instrument issues or purchasing new equipment, all but one of the 125 sites were confirmed to be measuring $\mathrm{D}_{\mathrm{LCO}}$ and alveolar volume accurately. A similar multisite study asked the PFT laboratories to use the $\mathrm{D}_{\mathrm{LCO}}$ simulator every 8 weeks. Over $16,000 \mathrm{D}_{\mathrm{LCO}}$ simulations were performed. Systems outside of control limits (3.0 units) were detected on $5.8 \%$ of tests. Significant differences were noted in inter-device average, with ranges from -5.0 to $+2.1 \%$. Higher inspired volume and higher alveolar volumes were associated with larger $\mathrm{D}_{\mathrm{LCO}}$ differences. Larger $\mathrm{D}_{\mathrm{LCO}}$ errors were noted for device temperatures $<21^{\circ} \mathrm{C}$ and $>27^{\circ} \mathrm{C}$.

A clinically important difference in $\mathrm{D}_{\mathrm{LCO}}$ from one visit to another in patients with interstitial lung disease or pulmonary vascular disease is considered a change of $\sim 15 \% .18-22$ The long-term reproducibility of the instrument, as estimated by the biological control testing of the 
healthy technologist (95\% of the values within 3 units of her mean $\mathrm{D}_{\mathrm{LCO}}$ and a coefficient of variation of $5.4 \%$ ) suggests that clinicians retesting patients during follow-up visits in a laboratory with good quality control could be highly confident that a measured change of $>15 \%$ is outside the measurement noise and is clinically important.

There are some limitations with the use of the $\mathrm{D}_{\mathrm{LCO}}$ simulator. The device relies on the delivery of a precise volume of test gas and also depends on the test gas being extremely accurate. Since a syringe delivers the volume, any damage could alter the volume of test gas to the tested instrument. Operator errors (eg, software settings, valve initiations) in the $\mathrm{D}_{\mathrm{LCO}}$ simulator will alter the desired targets. The precision test gas has to be mixed via a gravitational method, as opposed to via filling pressures, which is much more accurate. This ensures that the gases in the simulator gas have tolerances that will not affect the desired target $\mathrm{D}_{\mathrm{LCO}}$. Estimates of the errors for both volume and simulator gas in $\mathrm{D}_{\mathrm{LCO}}$ targets are $\sim 1 \%$.

\section{Conclusions}

Measurements of $D_{\text {LCO }}$ were stable over the 3-y period without any need for manual recalibration of the instrument. The biological control was as good as the $\mathrm{D}_{\mathrm{LCO}}$ simulator to evaluate this kind of device in a long-term laboratory quality control program.

\section{REFERENCES}

1. Pellegrino R, Viegi G, Brusasco V, Crapo RO, Burgos F, Casaburi $\mathrm{R}$, et al. Interpretative strategies for lung function tests. Eur Respir $\mathrm{J}$ 2005;26(5):948-968.

2. Wanger J, Irvin C. Comparability of pulmonary function results from 13 laboratories in a metropolitan area. Respir Care 1991;36(12): 1375-1382.

3. Borg BM, Hartley MF, Bailey MJ, Thompson BR. Adherence to acceptability and repeatability criteria for spirometry in complex lung function laboratories. Respir Care 2012;57(12):2032-2038.

4. Gochicoa-Rangel L, Torre-Bouscoulet L, Martínez-Briseño D, Rodríguez-Moreno L, Cantú-González G, Vargas MH. Values of impulse oscillometry in healthy Mexican children and adolescents. Respir Care 2015;60(1):119-127.

5. Gochicoa-Rangel L, Vargas-Domínguez C, García-Mujica ME, Bautista-Bernal A, Salas-Escamilla I, Pérez-Padilla R, Torre-Bouscoulet L. Quality of spirometry in 5-to-8-year-old children. Pediatr Pulmonol 2013;48(12):1231-1236.

6. Gallo HM, Crapo RO, Jensen RL. Monitoring carbon monoxide diffusing capacity devices with a simulator. J Investig Med 2007; 55(1):S153.
7. Miller MR, Hankinson J, Brusasco V, Burgos F, Casaburi R, Coates A, et al. Standardisation of spirometry. Eur Respir J 2005;26(2):319338.

8. Macintyre N, Crapo RO, Viegi G, Johnson DC, van der Grinten CP, Brusasco V, et al. Standardisation of the single-breath determination of carbon monoxide uptake in the lung. Eur Respir J 2005;26(4): 720-735.

9. Pérez-Padilla R, Valdivia G, Muiño A, López MaV, Márquez MaN, Montes-de-Oca Ma, et al. Valores de referencia espirométrica en 5 grandes ciudades de Latinoamérica para sujetos de 40 o más años de edad. Arch Bronchoneumol 2006;42(7):317-325.

10. Crapo RO, Morris AH. Standardized single breath normal values for carbon monoxide diffusing capacity. Am Rev Respir Dis 1981;123(2): 185-189.

11. Neas LM, Schwartz J. The determinants of pulmonary diffusing capacity in a national sample of U.S. adults. Am J Respir Crit Care Med 1996;153(2):656-664.

12. Haynes JM. Comprehensive quality control for pulmonary function testing: it's time to face the music. Respir Care 2010;55(3):355-357.

13. Punjabi NM, Shade D, Patel AM, Wise RA. Measurement variability in single-breath diffusing capacity of the lung. Chest 2003;123(4): 1082-1089.

14. Hegewald MJ, Markewitz BA, Wilson EL, Gallo HM, Jensen RL. Single-breath diffusing capacity for carbon monoxide instrument accuracy across 3 health systems. Respir Care 2015;60(3):430-436.

15. Wise RA, Teeter JG, Jensen RL, England RD, Schwartz PF, Giles DR, et al. Standardization of the single-breath diffusing capacity in a multicenter clinical trial. Chest 2007;132(4):1191-1197.

16. Jensen R, Leyk M, Crapo R, Muchmore D, Berclaz PY. Quality control of $\mathrm{D}_{\mathrm{LCO}}$ instruments in global clinical trials. Eur Respir J 2009;33(4):828-834.

17. Jensen R, Make B, Regan E, Silverman E, Crapo J. COPDGene intra-subject variability of $\mathrm{D}_{\mathrm{LCO}}$ measurements using an ultrasoundbased instrument. Eur Respir J 2015;46(Suppl 59):PA1028.

18. Moore OA, Proudman SM, Goh N, Corte TJ, Rouse H, Hennessy O, et al. Quantifying change in pulmonary function as a prognostic marker in systemic sclerosis-related interstitial lung disease. Clin Exp Rheumatol 2015;33(4 Suppl 91):S111-S116.

19. Novelli F, Tavanti L, Cini S, Aquilini F, Melosini L, Romei C, et al. Determinants of the prognosis of idiopathic pulmonary fibrosis. Eur Rev Med Pharmacol Sci 2014;18(6):880-886.

20. Raghu G, Collard HR, Egan JJ, Martinez FJ, Behr J, Brown KK, et al. An official ATS/ERS/JRS/ALAT statement: idiopathic pulmonary fibrosis: evidence-based guidelines for diagnosis and management. Am J Respir Crit Care Med 2011;183(6):788-824.

21. Miguel-Reyes JL, Gochicoa-Rangel L, Pérez-Padilla R, TorreBouscoulet L. Functional respiratory assessment in interstitial lung disease. Rev Invest Clin 2015;67(1):5-14.

22. Selman M, Undurraga A, Buendía-Roldán I, Caro-Fabián M, Curbelo P, Mejía M, et al. Recomendaciones para el diagnóstico y tratamiento de la fibrosis pulmonar idiopática. Respirar. https:// www.alatorax.org/formacion-profesional/respirar-newsletter-alat/ recomendaciones-para-el-diagnostico-y-tratamiento-de-la-fibrosispulmonar-idiopatica-2015. Accessed August 18, 2016. 